Human Factors Affecting the Use of Video Recording Methodology in Qualitative Research.

\author{
Sorrel Penn-Edwards \\ Griffith University \\ Queensland Australia
}




\begin{abstract}
The almost unlimited capacity of video to record visual images under wide ranging conditions has ensured that it has become an indispensable agent in research, particularly for qualitative investigation. Like other research tools its use is bounded by the methodology and its physical limitations. Unlike quantitative investigation however, its efficacy is dependent on the influence of human factors on the processes of data collection, analysis, and interpretation. The scientific and practical implications for good practice in qualitative research are discussed and a working framework, the outcome of the author's phenomenographic work, proposed.
\end{abstract}

Key words: Video research methodology, affective factors, collection and analysis of data, phenomenography 


\section{Human Factors Affecting the Use of Video Recording Methodology in Qualitative Research.}

\section{INTRODUCTION}

Traditional methods of data collection and analysis have been modified and extended by the availability of visual evidence (Flick, 2009; Harrison, 2004), and the distinction between quantitative and qualitative methodologies emphasised.

In quantitative investigation visual methodologies are objective, straightforward, unambiguous, well understood and in accord with scientific and mathematical principles. Qualitative investigation, however, involves observation of transitory phenomena with video recorded events aiming to capture and identify images of the truth which may be hidden. This is contentious since truth varies with ambient environment, viewing perspective, recording techniques and any bias by the researcher. This raises a number of methodological questions including: who makes the decisions as to what is included in the recording; how choices of angle, framing, lighting and so on may influence the presentation of the recorded image; which version of the truth is captured; and whether the act of recording itself affects the action or events being recorded (Davies, 2008, pp. 120-122; Denzin, 1989, pp. 213-214; Flick, 2009, p. 241).

The value of video is not in doubt but as Hall (2007) states "the rapidly expanding technical practices of such work should be anchored in systematic, established field research methods that have been developed by and taught to educational researchers over the past several decades" (p. 4). Over the years this has been an area of interest to semioticians, philosophers, and psychologists but they contain matters of substance that should be examined in detail in all qualitative research which uses visual data. As Flick (2009) says, consideration should not just be "with analyzing video material, but also with how a corpus of material is produced, which can then be analyzed" (p. 249).

The use of video, as with any method of research data collection, is initially evaluated in terms of usefulness, validity, ethicality, participant reactions and interaction, coding of data, and so on. In considering the foregoing the 
question of trustworthiness arises, that is, can the video evidence when audited be regarded with "credibility, transferability, dependability, and confirmability ... [which] are analogous to 'internal validity', 'external validity', 'reliability', and 'objectivity' in conventional criteria” (Oka \& Shaw, 2000, Section 7.2).

The requirement of validity is compromised when it is believed that the "the process of observing and recording research participants with a video camera has little or no influence on the data which is collected" (Lomax \& Casey 1998, Section 2.1), or that "the video camera has a uniquely distorting effect on the researched phenomenon and implicitly, the 'naturalness' of social reality" (Section 3.1). Lomax and Casey suggest that a more satisfactory resolution would result if researchers "address[ed] the way in which the process of data collection helps socially construct and produce the data that is collected" (Section 1.4).

Shrum, Duque and Brown (2005) also discuss this aspect of video in data collection and provide an "overview of digital video methodology" (para. 3) stating that as "visual artefacts and behaviours become as prominent as the words that the subject utters" then "researchers must learn a new set of technological and cognitive skills (planning, shooting, and editing digital video); ... they must negotiate more complex research protocols that include human subjects considerations" (Conclusion, para.1).

More prosaic issues concern the technical and operational items of planning and executing data collection. Detailed general guidelines on production practices may be found in such texts as Voice \& Vision (HurbisCherrier, 2007) and Master Handbook of Video Production (Whitaker, 2002) and for specific educational reference see Guidelines for Video Research in Education (Derry, 2007). Appropriate equipment type, lighting, placement and so on are discussed in "Visual evidence in qualitative research: The role of videorecording" (Penn-Edwards, 2004). Computer technology has provided new ways of coding, filing and storing visual data and this is also much discussed (Harper, 2005; Hughes \& Franks, 2008; Knudson \& Morrison, 2002, pp. 200-218; see in particular Parmeggiani, 2008 with reference to semiotic, ethnographic and visual sociology analysis). 


\section{HUMAN AFFECTIVE FACTORS}

Whilst video appears to present a valid record of events ideal for qualitative research purposes, it should be recognized that individuals using it respond in different ways to external stimuli (Davies, 2008; Flick, 2009; Rose, 2008). Whether participating in video recorded activity as participants, managing production or viewing the presentation, in each case a subjective reaction is induced with a risk that data may be prejudiced in its interpretation.

Some researchers are reported as believing visuals provide authentic communication data (Shi, Corcos \& Storey, 2001, p. 269) disregarding extralinguistic and cultural cues (Feak \& Salehzadeh, 2001, p. 490). Most viewers tend to accept the image as reflecting actuality, a facsimile or even an approximation of it (Feak \& Salehzadeh, 2001, p. 482). The absence of olfactory and kinaesthetic experiences, and the limiting of spatial perception by the selective framing of images increases the complexity. Visual anthropologists and sociologists point out that "all visual representations are not only produced but are consumed in a social context" (Banks, 1995, para. 11).

Video clearly has "considerable methodological value ... as long as an awareness of the status of the data is maintained" (Lomax \& Casey, 1998, Section 8.3) therefore "such work should be anchored in systematic, established field research methods that have been developed by and taught to educational researchers over the past several decades" (Hall, 2007, p. 4).

\section{Consideration of affective factors}

In the design of research projects the relationship of the researcher, with respect to independence, impartiality, and objectivity, is stated clearly and unequivocally. However when employing video it raises questions about the role of the subconscious in decision making.

\section{Point of recording}

Before a recording session there are practical measures to be organised such as setting, background appearance, lighting array, framing format of images, required number of recorders and their mobility in use (hand held, fixed tripod etc). Decisions about these should be made from three perspectives: research (How obtrusive is using a light on a stand compared to using ambient 
light?); production (Is the ambient light bright enough to illuminate the required detail of the subject?) and affective.

It is clear that in published discussions about research methodology the setting is selected with regard to its presumed familiarity to the subjects being recorded and to the support this gives to them gaining confidence and maintaining an equable disposition. From an affective perspective semiologists theorise that the environment apparent in a visual may also influence its perceived reality (Rose, 2008, p. 82 ), even if it is seemingly irrelevant to the analytical process.

From a production perspective, it should be ensured that the lighting of a subject is sufficient to produce useable images for observation and analysis but not so that it constitutes a distraction to the subjects. Like the background to a visual the many properties of lighting can unconsciously introduce a theatrical and false interpretation of an image due to intensity, colour, contrast, reflection and shading. It is a truism of poststructuralist theory that bright light evokes "feelings of security and happiness" and dim light triggers "a sense of powerlessness" (Silverblatt, 1995, p. 95) whilst the overall colour cast can exert an emotional or psychological charge, such as a blue hue inducing a feeling of coolness and calm (Wilson, 1998, pp. 349-350).

The framing format of a recorded visual is dependent on what the researcher aims to capture or emphasise; a close-up for small changes in facial expressions; a wide frame for action among a number of subjects. Any mediated visual image is composed of a number of semiotic elements which may have a direct affect on viewers but of which they are unaware (Pramaggiore \& Wallis, 2005, pp. 121-122). An ill considered choice of framing format at a point of recording may have unintended consequences at the point of viewing. Apart from the obvious ability to see more or less detail, "degrees of formality are reflected in shot size" (Chandler, 2007, p. 193). Close-up framing encourages a feeling of intimacy with the subjects, and a wide horizontal framing introduces a distancing not just of the subject from the environmental context, but between the viewer and the subject. Handholding the camera engenders an amateur or home movie feeling and because the visual is not stable it is often perceived as 
unpremeditated, an indicator of reality whereas a smooth professional looking recording may be perceived as set up. Other affective factors, known to semioticians as visuals codes (Chandler, 2007, pp. 164-165) include the shape (or form) and scale of the subject's position relative to others and to the boundaries of the viewing frame. The latter relates to the direction of eye reading, an inherent cultural feature, and unconscious identification of relative power and authority. The perceived point of view also depends on the recorder's eyeline during recording such that viewing a subject above confers authority and below it inferiority.

\section{Point of editing}

All video is edited to some extent as even inclusions or omissions during recording contribute to the modified character of the actual event. Post-recording editing can reorder material in time and space, or in arrange it in various hierarchies of importance or relationships. Study of the etymology of editing shows the semiotic connotations implicit in selection, sequencing, special effects and the like. Nack and Parkes (1997, p. 58) state that such factors as the demographic attributes of the editor (e.g. male, adult, etc), nature of personality, and a degree of empathy with the target audience together with external cultural and social mores are influential in affecting editorial practice.

\section{Point of viewing}

At the point of viewing concerns may centre on aspects of confidentiality, reliability and validity of coding techniques. In production this would include optimum viewing facilities and workable analytical processes. However, factors such as a viewer's life experience, gender, cultural roots and degree of socialisation may also be relevant in the interpretation of a video recorded image. This is particularly so when a subject has like or opposite physical and behavioural characteristics to the viewer. Familiarity with the context of the image, partiality to the techniques of presentation, and the relative impact of facial expressions, can also be factors. As Davies (2008) suggests, although "the validity of the visual is addressed from within the processes of production ...it also needs to be considered as a matter of visual literacy, of educating critical viewers" (p. 118). 
It can be seen that at each stage of its use, decisions are made about video recording that may affect the collection and interpretation of data and whilst objective proposals (quantitative) are generally well understood when subjective issues arise (qualitative) the same certainty does not exist and issues are contentious.

Although all documented research procedures acknowledge the need to accurately report the methodology and nominate the instruments used in collecting, collating and analysing data many researchers "treat visual evidence as comparatively unproblematic ... [being] regarded in an uncritical realist perspective" (Davies, 2008, pp. 120-121). As well as the scheduled details of production (day, dates, time, place, etc), Marshall and Rossman (2006) state that "the photographer's intent and interests" (p. 120) should be recorded when visuals are used as part of a research methodology. No matter in what field of study or the methodology used reporting of the video's use should show deliberation in planning and execution at the points of recording, editing, and viewing.

\section{FRAMEWORK FOR INVESTIGATING THE ROLE OF HUMAN AFFECTIVE FACTORS}

With the increase in use of video recording in which qualitative matter and subjective evaluation predominate the research methodology of phenomenography was considered apposite.

Phenomenography is "an interpretive research approach that seeks to describe phenomena in the world as others see them" (Bruce, Buckingham, Hynd, McMahon, Roggenkamp \& Stoodley, 2004, p. 145) in this case, how researchers using video in their work conceptualized the phenomenon of video. The focus of a phenomenographic interview is on responses "expressing conceptions of objects or phenomena and the ... interviewees delimitation and experienced meaning of these objects" (Marton, 1994, p. 18). In order for these expressions to remain centred in their life-world the role of the interviewer must be one of facilitation rather than direction so interviews were unstructured with responses invited to a generalised initial query. The open-endedness of this approach in phenomenography is highlighted by Bowden (2000) as it allows "the 
interviewees to decide the aspects of the question which appear most relevant to them. The interviewees' approaches to the question and the aspects they choose to consider are of relevance in the analysis of the transcripts" (p. 8).

The following outlines a framework for exploring and reporting on the human affective factors that are present when video technology is used in qualitative research. The study was approved by the university and each participant granted permission on a standard privacy statement and the transcripts of the audio recordings of interviews were coded to ensure confidentiality. Twenty individuals, academics and postgraduates, from two Queensland Universities across six faculties who had used video recording as part of their research were selected covering a range of academic fields keeping an equal balance of gender and spread of age.

\section{The framework of the study}

Bruce (1994) suggests three ways to enhance the defensible validity of the phenomenographic interview: that the questions are designed to orient the interviewee towards the phenomenon; that the interviewee is encouraged to describe his/her understanding of the phenomenon "through examples, descriptions of previous experience etc"; and that the interviewee is aware of the experiential nature of the interview and responds from their personal experiences (p. 54). In accord with phenomenographic practice the interviewer actively pursued "bracketing" her own experiences of the phenomenon during the interview by "focusing on the views or experience of the interviewee" and abided by the "rule of horizontalization" by "treating all possible pictures supplied by the interviewee as being of equal value" (1994, p. 54).

Analysis of the transcripts was undertaken following the phenomenographic framework of Dahlgren and Fallsberg (1991). The first two steps were to achieve a familiarisation of the transcripted material and then a condensation of the transcripts by choosing significant statements to form a "data pool" (Marton, 1986, p. 43). The resultant "data pool" is supported by analysis of the transcripts by two independent analysts. The transcripts were perused and significant statements about video were identified and extracted. Particular notice was taken pertaining to gestures and the context of statements 
as well as the tone used by the interviewee and the purported meaning given at the time.

In order to gain validation of the process at this stage, ten transcripts were given to two independent analysts for perusal; five of these transcripts were common to both. Sections mentioning video were highlighted to aid the reader but were not delimiting. The analysts' brief was generalised and non-directional. They were asked to read through each transcript and to briefly note any significant statements made by the interviewee. Of the significant statements selected by the original analyst only $4 \%$ were not similarly selected by the independent analysts.

The first step in the analysis was to compare the selected statements to find variation or agreement being "focused on identifying and describing the [contained] conceptions in terms of their overall meanings. This was done by marking and segmenting the transcripts according to the themes addressed" (Marton \& Pong, 2005, p. 337). These statements were then thematically grouped, like-to-like in a re-iterative process, a group being "formed whenever there was sufficient evidence that a particular overall meaning had been expressed" (Marton \& Pong, 2005, p. 337). Six groups were examined in order to articulate the essence of similarity of the grouped statements and then were labelled using key terms extracted from the grouped statements - these are known as categories of description. Each category of description is discussed, described, and supported by quotations from the transcripts. The validity of these categories of descriptions is supported by an independent co-judge who classifies the statements identified in a number of transcripts according to the specifications of the categories of description. The confirmed categories of description were applied systematically to the four hundred and sixty-five significant statements made by the interviewees and conclusions drawn from the findings.

Phenomenographic co-judging is a means of testing that the categories of description can be communicated to others and this is deemed successful if the co-judge - an independent person external to the study underway - is able to "classify the statements made by interviewees in the same way as the 
researcher has done" (Säljö, 1988, p. 45). This co-judging occurs after the categories of description have been identified and illustrative quotes chosen and listed under each category. The co-judge is asked to place a number of quotes from the transcripts into the identified categories of descriptions. A high rate of matching is required for validation, and this is achieved through discussion between the researcher and the co-judge. The degree of coincidence in this research between the co-judge and the author was $86 \%$.

The six categories of description drawn from the interview data covered either video recorded data or the process of recording and viewing video (people and equipment) and can be identified as being grounded in specific practicalities or with abstract processes. Video in the former instance was centred on certain practicalities and conceptualised by users as: a means of containing knowledge and skills in a package - Video as a Package; a way of allowing the user to be engaged in research - Video as Elemental; a series of problems for the user Video as Problematic. In the second case video was centred on the abstract and was seen by users as: a method of allowing them to access various skills and knowledge - Video as an Augmentation; a process that had an affect on people's behaviour etc. - Video as a Facilitation; and as a technique allowing them to see some portion of real life - Video as an Aspect of Reality.

These six categories of description can be related to each other logically and shown in a structure known phenomenographically as "the outcome space". This is "metaphorically speaking - a map of a territory in terms of which we can interpret how people conceive of reality" (Säljö, 1988, p. 44), a diagram which allows a reader to see the differences between the categories and the relationship between them.

[Insert Figure 1 here]

The range of conceptions held within each category of description underlines the need for careful consideration and reporting when using video recording as part of any research methodology so that the beliefs of the user are clear. 


\section{Practicality: Video as a package}

Video is a physical entity which in the form of a package of data is able to be transferred to other people and locations. It is seen as a process whereby researchers control the transference of the packaged data. Their beliefs about video as a package emphasises different aspects of its function, summed up by a researcher who said "you could exploit such a little machine like the video for so many tasks" (Interview 10/120). It was particularly mentioned that data is able to be video recorded at one time and place and shown at a different time and place; a particularly useful function because "I can't get them to come to class at the time that I want them to do it live, so I'll video them" (Interview 1/62). It can also provide privacy so that users can "work on their own without working with a whole pile of people in a public place" (Interview 2/87). Comment was also made that it can be shown to many viewers at different times, and in different places and that "you can send it away to any number of moderators and they all see exactly the same thing" (Interview 1/258). It was also used by way of promotion with researchers saying: "I take videos along and show them ... what we're doing as scientists ... 'is that what you're doing, I didn't realise"' (Interview $20 / 117,133,147)$. In addition it is seen as "a very powerful stimulus for making us remember what happened" (Interview 15/255) with researchers commenting that they have replayed video recordings to prompt reflection and stimulate recall.

As a package there is the opportunity to view the video recording many times, allowing a more detailed interpretation of the material, "doing finer and finer and finer analysis or going in and doing different kinds of analysis" (Interview 4/244). It is also noted that each viewer can interpret the same video from a different standpoint and that "you use different elements or different sections of footage to satisfy multiple needs" (Interview 3/336).

\section{Practicality: Video as Elemental}

Researchers saw video as being elemental, that is, essential to collecting data for effective research and moderating research procedures with one claiming that it "had an impact on lots of studies and research" (Interview 15/44). The interviews revealed that some researchers were of the opinion that "sign language recognition itself has been around for about as long as video has, so 
they sort of came hand-in-hand" (Interview 1/83), and "those sort of ordinary technological advances that enable us to do research that would have been not impossible but certainly much more difficult to do before video" (Interview 4/240). In the role of instigator and proponent of research methodology researchers claim that "it is one of the biggest boons to theorising and research in the area of language development" (Interview 13/314), a stimulator of research in that "watching [it on video] ...gave us the idea of how to [do it] ... it's opened up a brand new field in this area" (Interview 20/70, 86).

It was recognised that video was a necessary and legitimate component of formal research methodology (Interview 6/69, 169) providing more data than journals or audio recordings (Interview 13/43, 344), used "because we know that there are shortfalls in other research methods" (Interview 14/27, 444).

\section{Practicality: Video as Problematic}

Although perceived as elemental video it is also seen as a process containing problems overt and implied which must be anticipated and planned for. At the point of recording these may include trial and error procedures, questionable directions in camera operations, a necessity for current texts on production matters, and at the point of viewing, the standard or preferred quality and quantity controls related to analysing video data. It is an active process, the user controlling the video within the usually limited knowledge or experience of the researcher; thus practicality predominates. Researchers often take different roles in each functional step of the recording process; as camera operators their comments centre on the need to learn techniques of video recording in a selflearning mode citing examples such as "[l] got it wrong a lot in the beginning, so I learnt from all of my mistakes" (Interview 1/423), "I learnt because I had to and I don't want to have to be reliant upon having somebody else be there ... so it was easier if I learnt how to do it myself" (Interview 1/122). These attitudes were summed up by the statement that "if there [had been] ... someone with expertise around who we could draw on, it'd remove the trial and error type approach" (Interview 18/201).

As a producer, with others as camera operators, comments centered on the necessity of obtaining advice from texts, "read the manuals, 
that's how I learnt to use the video camera" (Interview 1/154), or from AV personnel or experienced users, "we had to train the research assistants to use the cameras" (Interview 11/43), thus "to use videos... [it] is going to take quite a lot of planning and expense" (Interview 5/209). However having someone else as a camera operator exposes other problems as "if you have someone operating the camera, what you end up seeing is what they've chosen for you to see" (Interview 19/731). There are also concerns about participants' reactions to aspects of the recording process, "she seemed to have the notion somehow that they [as subjects] were being tested somehow and being given a score [and wanted the child to behave properly]" (Interview 13/262), and particularly the intrusiveness of the camera, "it takes a lot of preliminary work so that the video itself isn't intrusive" (Interview 14/90).

Difficulties were exposed during analysis such as criticism of a generic nature "that is a problem with analysis of data ... not just with video, I mean mind sets about what we expect to see can lead us astray" (Interview 4/412), of video specifically such as amount of data generated which is "too labour intensive" (Interview 14/438), or of coders who "can't use the video machine very well" (Interview 5/269). This frustration lead to the comment "it has got to a stage where we say to ourselves why can't we just send out a questionnaire" (Interview 6/557).

\section{Abstract: Video as being an Augmentation}

Beyond being a basic tool essential for any qualitative research video recording is also seen as augmenting the process of data collection, a means of extending comprehension and power when recording. Users observed that it "gives you other senses that one uses" (Interview 5/638) and "I really got a sense of everything that was happening" (Interview 9/320). The feeling expressed is that "any practitioner would come into a greater understanding ...when you watch those video of themselves again and again" (Interview 19/615) and that "[recording myself on video] helped me work out what I should be telling the students so I learned as much from [making] the video as I think that the students did [from watching]" (Interview 2/112). When the recorded material is viewed a common sentiment expressed by users is that "you are able 
to replay, replay and rethink about the significance of what you think has happened and make an interpretation ... really feel that you are understanding what is going on in the situation" (Interview 5/407,640) .

In using video for augmentation it is seen as allowing researchers to take on different roles or duties, "having the video [recording the event] I could actually look at what he was doing [at the time instead of taking notes]" (Interview 9/322). In some instances it is referred to as a researcher in loco, "video ... to be a critical friend in the classroom" (Interview 3/34) and "I use the video camera as my participant observer or my observer ... it's like having a third person in the room" (Interview 19/805,626). Video recording is also promoted as an alternative to a human agency as it appears to be not so obtrusive, "my research assistant can turn it [the camera] around and she can watch what they are doing without watching them ... because you know what children are like when you are watching them, it sort of inhibits them" (Interview 6/121) and "had the video not been there I would have had no idea what they were doing ... I don't think that particular episode would have happened had I or a researcher been in the classroom as well" (Interview 19/240,430).

\section{Video as a Facilitation}

Video is also considered to ease facilitation of new understandings and realisations. It affects the individual directly in that it allows them to be "confronted with their actions ... a very potent way of allowing the [participant] to reflect" (Interview 14/64, 71) and indirectly, as "you become part of what happens on the screen in the video because of the connection ... to previous knowledge and ... you make an identification" (Interview 10/264).

Learning through the use of video occurs in two modes, through individuals operating the video camera themselves, "the learning experience [producing a video]... was great for the students ... they were strongly engaged in this task to make something what is meaningful for them because they knew that the end product will be useful" (Interview 10/186,207), and through watching video recordings, it is "a really salient way of getting beginning teachers into the heads of effective teachers ... [as it] reveal[s] what this teacher thought he was doing" (Interview 14/128,370). This perception is summed up in "I went out and 
videoed him ... [when he saw the video] it was like a light came on and he said 'oh so that's what they were talking about' ... which he swears he couldn't see beforehand until he saw it himself" (Interview 12/66).

\section{Video as an Aspect of Reality}

This category of description shows how researchers interviewed in the study saw video recordings as an aspect of reality, and revealed a variety of conceptions. The most simple explanation is found in the statement "if I can see it, I can believe it" (Interview 3/262), that is the user saw it as a device which "records everything" (Interview 6/90); the videoed images being "real ... a frozen moment ... in time" (Interview 3/194, 206, 277) and as providing "a concrete, measurable and accurate record ... that we could work from" (Interview 19/155). It was believed it could replace personal observations and experience "to provide students with ... socio-cultural background knowledge" (Interview 10/245), and shown so that "so people who can't experience [it] will see first hand" (Interview 20/40). It was stated categorically that it gives a "very, very, good representation of [the] data ... it is a slice of life" (Interview 14/290,566), the user "really getting a sense of everything that was happening" (Interview 9/320).

Not all researchers were so sure that video could ever be more than a partial record of an event, a sample or a segment, "an imperfect picture of what went on, where necessarily you are looking at one aspect" (Interview 14/23). There was a realisation that "there is only the opportunity for one of a universe of options to be realised" (Interview 5/128, 307) and an acknowledgement that "it still only captures a perspective" (Interview 12/378). This is exemplified by the comment that it is "difficult to work as a [sign] interpreter from a two dimensional mode [on video] when you're used to seeing it three dimensionally [in actuality]" (Interview 1/224). A user uneasily aware that the video recording may not have captured something of importance occurring in the actual event says it is with a "sneaky feeling that some students may well have been doing other things" (Interview 11/153) beyond the video camera's reach, "you can never recapture the experience, but I think that when you have a video of the experience you can kind of remember" (Interview 19/789). Many researchers recommended that video recording be used in conjunction with other methods of recording or 
presenting, such as note taking and participant's journals (Interview 7/64, 264) or post recording reflections (Interview 12/219).

Video is also recognised as providing insight into any event, a means of seeing more than is practically observable at the time of the actual event particularly when one is coding (Interview 4/301), seeing unexpected happenings (Interview 8/336), and arriving at new realisations (Interview 19/423) because it allowed "the reasoning, ideas, conceptual understandings, subtle nuances and relationships to be exposed" (Interview 9/406). These advantages are summed up in "I actually think the video is a really good method of being able to abstract such things ...like the mood of the class and the tension of the class ... you get a sense of that when you watch through a video" (Interview 19/523).

\section{DISCUSSION}

The phenomenographic study presented demonstrates that researchers using video hold a range of conceptions about how they perceive video its functions and offerings. Sorting the transcripted interview data into six thematic groups showed that video was discussed in relation to specific practicalities or to abstract processes, and described either the video recorded data itself or the process of recording and viewing video. Ordinarily this would be of no surprise, but it is how researchers reach their conclusions that holds particular interest for the phenomenographer.

Video as an object is seen as a way of containing knowledge and skills in a package and as a means of allowing the user to be engaged in research, whilst at the same time it is found to present a series of problems. The foregoing may appear to be straightforward understandings with comments ranging according to the status of knowledge and experience of the researcher. However the categories of descriptions under practicalities (Figure 1) are implicitly linked to the other categories of descriptions headed abstract (Figure 1) where the conception of video is that it has an affective influence. When researchers speak of video as an integrated process, a method of allowing them to access various skills and knowledge, they invest it with extra properties, to some it generates an extra sensory perception, almost a fourth sense - the actual word "sense" being used, unprompted, by many of the researchers interviewed. 
This perspective of video is extended in the category of description where video not only augments the research process but is seen as helping, directly and indirectly, to achieve new realisations about themselves (the researchers) and the people and processes recorded. It is almost personified as a beneficial being who guides insightfulness - or as many of the researchers said it "allows" various insights to take place. The sixth and final category of description would seem to underlie most of the conceptions identified above. All researchers using video as part of qualitative research hold certain beliefs that a video recording made of an event shows an apparent authentic version of the real event: a facsimile, an approximation, an illustration of actuality, or even reality itself. This belief, which is rarely voiced by the researcher outside of ethnographic or media studies, affects not only the interpretation of the visuals but decisions made at each point of video usage. Researchers who say "if I can see it, I can believe it" (Interview 3/262) may use video quite differently in their work than those who say that video provides "an imperfect picture of what went on, where necessarily you are looking at one aspect" (Interview 14/23). The former might believe that reactions to an on screen event are the same as those when witnessing the event itself. The latter might consider that the comfortable focused seating of the video viewer, muted audio, and the viewing environment may be nullifying.

\section{CONCLUSION}

The evidence offered confirms that video recording is regarded as indispensable in qualitative_research irrespective of views held about its role as an elicitor of truth and the means employed to obtain a sustainable analysis. The six categories of description offered in this paper are broad groupings of conceptions and researchers would certainly hold one or more of these at any one time during their use of video. These factors impinge on each other and are susceptible to affective influences, especially human insight and beliefs. In particular the belief that video recording captures the authentic version of reality is shared by many researchers using it in qualitative investigation. The researcher's conceptions may not have an effect on the outcome of the research, depending on the focus, but unless such aspects of the use of video are explicitly considered, evaluated, and reported the validity of qualitative 
research is open to question. The outcome space of the phenomenographic study described in this paper offers six simple nominated areas as a guide for all qualitative researchers in considering their own beliefs and as an aid in evaluating how this may affect their research when recording, editing, and viewing. It is incumbent on researchers that the methodology and their presumptions are fully described and evaluated. 


\section{REFERENCES}

Banks, M. (1995). Visual research methods, Social Research Update 11. Retrieved August 20, 2012, from http://sru.soc.surrey.ac.uk/SRU11/SRU11.html

Bowden, J. A. (2000). The nature of phenomenographic research. In J. A. Bowden \& E. Walsh (Eds.), Phenomenography (pp. 1-18). Melbourne: RMIT University Press.

Bruce, C. (1994). Reflections on the experience of the phenomenographic interview. In R. Ballantyne and C. Bruce (Eds.), Phenomenography: Philosophy and practice (pp. 47-56). Brisbane, Queensland: QUT Publications.

Bruce, C., Buckingham, L., Hynd, J., McMahon, C., Roggenkamp, M., \& Stoodley, I. (2004). Ways of experiencing the act of learning to program: A phenomenographic study of introductory programming students at university. Journal of Information Technology Education, 3, 143-160.

Chandler, D. (2007). Semiotics: The basics ( $2^{\text {nd }}$ ed.). London: Routledge.

Dahlgren, L. O., \& Fallsberg, M. (1991). Phenomenography as a qualitative approach in social pharmacy research. Journal of Social and Administrative Pharmacy 8(4), 150-156.

Davies, C. A. (2008). Reflexive ethnography: A guide to researching selves and others. London: Routledge.

Denzin, N. K. (1989). The research act ( $3^{\text {rd }}$ ed.). Englewood Cliffs, NJ: Prentice Hall.

Derry, S. (Ed.). (2007). Guidelines for video research in education. Chicago:

Data Research and Development Center, NORC at the University of Chicago.

Feak, C. B., \& Salehzadeh, J. (2001). Challenges and issues in developing an EAP video listening placement assessment: A view from one program. [Electronic version] English for Specific Purposes, 20, 477-493.

Flick, U. (2009). An introduction to qualitative research. London: Sage.

Hall, R. (2007). Strategies for video recording: Fast, cheap and (mostly) in control. In S. Derry (Ed.), Guidelines for video research in education (pp. 4- 
14). Chicago: Data Research and Development Center, NORC at the University of Chicago.

Harper, D. (2005). What's new visually? In N. K. Denzin \& Y. S. Lincoln (Eds.), The Sage handbook of qualitative research ( $3^{\text {rd }}$ ed., pp. 747-762).

Thousand Oaks, CA: Sage.

Harrison, B. (2004). Photographic visions and narrative inquiry. In M. Bamberg \& M. Andrews (Eds.), Considering counter-narratives: Narrating, resisting, making sense (pp.113-136). Amsterdam; Philadelphia: John Benjamins.

Hughes, M., \& Franks, I. M. (2008). The essentials of performance analysis: An introduction. London: Routledge.

Hurbis-Cherrier, M. (2007). Voice and vision: A creative approach to narrative film and DV production. Amsterdam: Focal Press.

Knudson, D. V., \& Morrison, C. S. (2002). Qualitative analysis of human movement ( $2^{\text {nd }}$ ed.). Champaign, IL: Human Kinetics.

Lomax, H., \& Casey, N. (1998). Sociological Research Online, 3(2), Article 1. Retrieved August 20, 2012 from http://www.socresonline.org.uk/3/2/1.html Marshall, C., \& Rossman, G. B. (2006). Designing qualitative research (4 ${ }^{\text {th }}$ ed.). Thousand Oaks, CA: Sage.

Marton, F. (1986). Phenomenography - A research approach to investigating different understandings of reality. Journal of Thought, 21(3), 28-49.

Marton, F. (1994). On the structure of awareness. In J. A. Bowden \& E. Walsh (Eds.). Phenomenographic research: Variations in method (pp. 89-100). Melbourne, Victoria: RMIT.

Marton, F., \& Pong, W. Y. (2005). On the unit of description in phenomenography. Higher Education Research and Development, 24(4), 335-348.

Nack, F., \& Parkes, A. (1997). The application of video semantics and theme representation in automated video editing. Multimedia Tools and Applications, 4, 57-83.

Oka, T., \& Shaw, I. (2000, September 21). Qualitative research in social work. Retrieved August 20, 2012, from http://pweb.sophia.ac.jp/oka/papers/2000/qrsw/ 
Penn-Edwards, S. (2004). Visual evidence in qualitative research: The role of videorecording. The Qualitative Report, 9(2), 266-277.

Pramaggiore, M., \& Wallis, T. (2005). Film: A critical introduction. London: Laurence King.

Parmeggiani, P. (2008). Teaching different research methods through the use of video analysis software for media students: A case study. International Journal of Multiple Research Approaches, 2, 94-104.

Rose, G. (2008). Visual methodologies: An introduction to the interpretation of visual materials. London: Sage.

Säljö, R. (1988). Learning in educational settings: Methods of inquiry. In Ramsden, P. (Ed.). Improving learning: New perspectives (pp.32-48). London: Kogan Page.

Shi, L., Corcos, R., \& Storey, A. (2001). Using student performance data to develop an English course for clinical training. English for Specific Purposes, 20, 267-291.

Shrum, W., Duque, R., \& Brown, T. (2005). Digital video as research practice: Methodology for the millennium. Journal of Research Practice 1(1), Article M4. Retrieved July 16, 2009 from http://jrp.icaap.org/index.php/jrp/issue/view/1/showToc

Silverblatt, A. (1995). Media literacy: Keys to interpreting media messages. Westport CT: Praeger.

Whitaker, J. (2002). Master handbook of video production. New York: McGrawHill.

Wilson, E. (1998). Three colours: Blue: Kieslowski, colour and the postmodern subject. Screen, 39, 349-36. 
Figure 1. Outcome space: Human factors affecting the use of video in qualitative research showing six categories of description

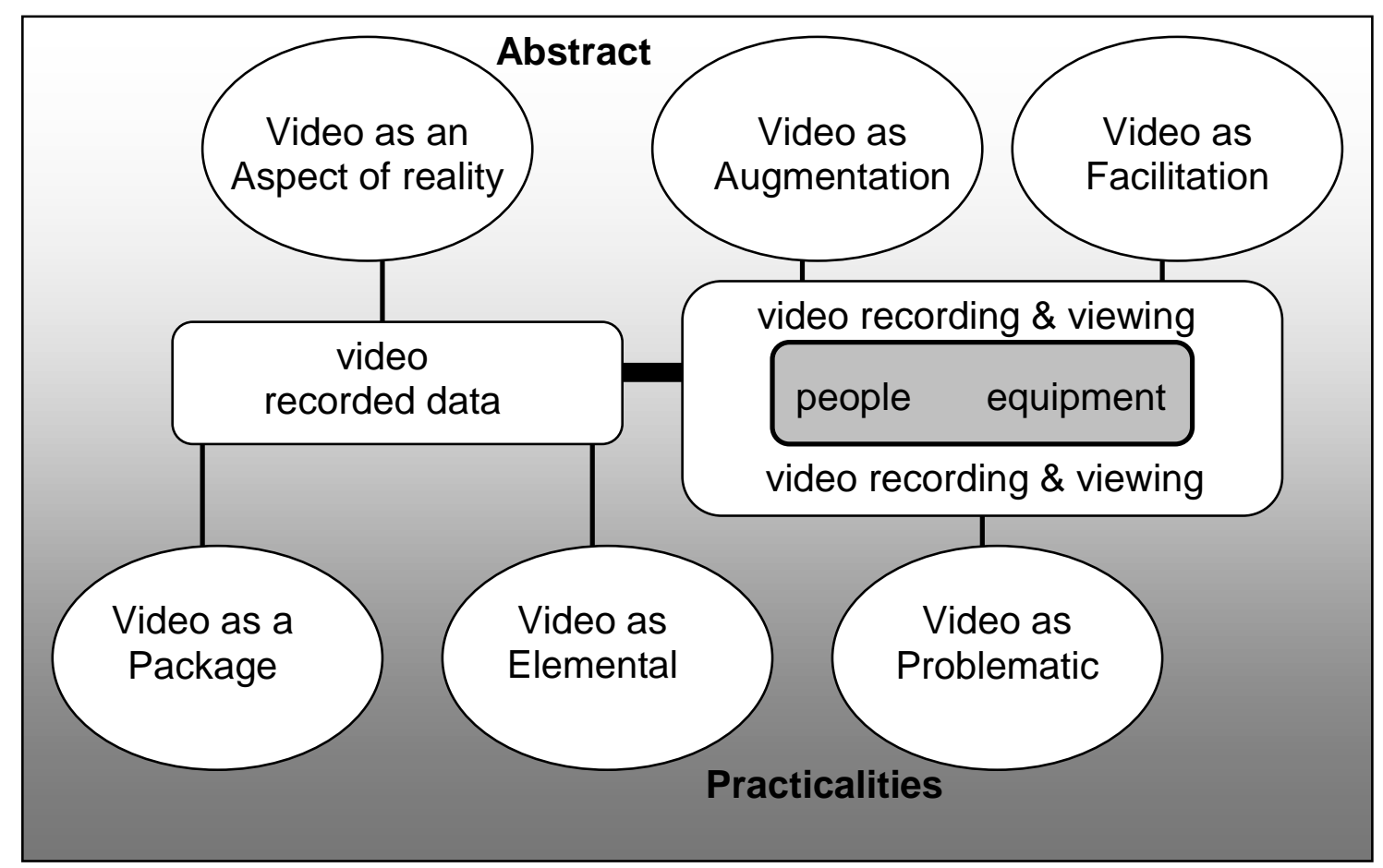

